\title{
Pengaruh Reward Dan Punishment Terhadap Kinerja Karyawan PT Unilever Indonesia Tbk. Jakarta Divisi Field Execution Management
}

\author{
Sri Sumarjati ${ }^{1}$, Sri Siswani ${ }^{2}$ \\ Program Studi Administrasi Bisnis Universitas Respati Indonesia \\ email:Sumarjati.sri86@gmail.com,siswanisri@yahoo.co.id
}

\begin{abstract}
This research is based on the formulation of the problem namely how is the effect of reward and punishment on PT Unilever Indonesia Tbk Jakarta (Field Execution Management Division) employee work performance. The purpose of this research is to find out how much influence the reward and punishments have on the work performance of on PT Unilever Indonesia Tbk Jakarta (Field Execution Management Division). With a sample of 61 people sampling using probability sampling, where the sampling technique uses simple random sampling. The Method Used In this research is a quantitative method and to analyze the data used a regression test and a simple linear correlation test. Data collection techniques are Observation, Interview, Questionaire, and Documentation obtained from respondents. The results of the research analysis showed that there was an influence effect of variable reward, variable Punishment on Variable Job Performance at on PT Unilever Indonesia Tbk Jakarta (Field Execution Management Division).
\end{abstract}

Keywords: Giving Reward and Punishment, Work Performance and Employees

\begin{abstract}
ABSTRAK
Pengaruh reward dan punishment terhadap kinerja karyawan merupakan kajian yang penting dilakukan karena reward dan punishment akan memiliki pengaruh untuk meningkatkan kinerja karyawan. Diharapkan dengan adanya reward dan punishmnet yang tinggi akan membuat kinerja karyawan optimal karena kinerja karyawan akan mempengaruhi produktivitas perusahaan. Penelitian ini bertujuan untuk menguji dan menjelaskan pengaruh reward terhadap kinerja karyawan, pengaruh punishment terhadap kinerja karyawan, serta pengaruh reward terhadap punishment pada PT Unilever Indonesia Tbk Jakarta Divisi Field Execution Management. Lokasi penelitian berada di DKI Jakarta. Teknik Pengambilan sampel adalah simple random sampling, yaitu seluruh populasi memiliki kesempatan yang sama untuk dijadikan sampel. Jumlah sampel adalah 61 responden. Kuesioner merupakan instrumen utama untuk mengumpulkan data primer. Analisis penelitian menggunakan SEM, SmartPLS 3. Hasil analisis penelitian menunjukkan bahwa terdapat pengaruh signifikan antara variabel reward, variabel Punishment terhadap Variabel kinerja karyawan pada PT Unilever Indonesia Tbk Jakarta Divisi Field Execution Management.
\end{abstract}

Kata Kunci: Reward, Punishment, Kinerja Karyawan 


\section{PENDAHULUAN}

Seiring dengan perkembangan ilmu pengetahuan dan teknologi, maka antara perusahaan yang satu dengan perusahaan yang lain akan bersaing dalam hal kualitas, baik itu kualitas peningkatan sumber daya manusia maupun kualitas produk, terutama antara perusahaan yang menghasilkan produk/ jasa yang sejenis. Peningkatan sumber daya manusia merupakan suatu kegiatan yang dilaksanakan bersama-sama karyawan dan manajer dengan tujuan mencari nilai tambah agar perusahaan tersebut dapat menghadapi tantangan kompetitif.

Selain itu, peranan tenaga kerja suatu perusahaan sangat penting karena tenaga kerja merupakan penggerak utama atas kelancaran usaha dan kinerja perusahaan karena merupakan salah satu asset (kekayaan) perusahaan yang harus dipelihara dan dijaga dengan jalan memenuhi kebutuhan dan keinginannya.

Untuk menjaga agar karyawan tetap berkomitmen terhadap perusahaan maka perusahaan harus tetap dapat memberikan kepuasan kerja bagi para karyawan dengan berusaha senantiasa memenuhi kebutuhan karyawan baik secara finansial maupun non finansial dan disertai berbagai macam fasilitas yang menunjang.

Pada dasarnya untuk melihat sampai sejauh mana peranan Sumber Daya Manusia dalam suatu perusahaan, maka dapat dilihat dari hasil kinerja seorang karyawan yang ada dalam perusahaan tersebut. Untuk dapat melahirkan sumber daya manusia yang berkualitas tidak saja diperlukan pekerja yang handal, melainkan juga perlu suatu proses yang mendukung terwujudnya pekerja yang produktif sesuai dengan yang diharapkan.

Kinerja karyawan merupakan hasil olah pikir dan tenaga dari seorang karyawan terhadap pekerjaan yang dilakukannya, dapat berwujud, dilihat, dihitung jumlahnya, akan tetapi dalam banyak hal hasil olah pikiran dan tenaga tidak dapat dihitung dan dilihat, seperti ide-ide pemecahan suatu persoalan, inovasi baru suatu produk barang atau jasa, bisa juga merupakan penemuan atas prosedur kerja yang lebih efisien.

Kinerja para karyawan sangat mempengaruhi keberhasilan suatu organisasi. Apabila kinerja karyawan baik, maka kinerja perusahaan akan meningkat. Sebaliknya apabila kinerja karyawan buruk, dapat menyebabkan menurunnya kinerja perusahaan. Dengan dukungan perusahaan dalam meningkatkan budaya organisasi, lingkungan kerja fisik, dan disiplin kerja yang memadai dapat memberikan dorongan kinerja yang lebih baik untuk para karyawan, sehingga perusahaan dapat mencapai tujuan yang diharapkan.

Salah satu faktor yang mempengaruhi kinerja karyawan adalah reward. Reward adalah ganjaran, hadiah, penghargaan atau imbalan yang bertujuan agar seseorang menjadi lebih giat lagi usahanya untuk memperbaiki atau meningkatkan kinerja yang telah dicapai. Apabila reward tidak sesuai maka akan sangat mempengaruhi kinerja karyaan kedepannya.

Selain faktor reward, faktor punishment juga sangat mempengaruhi kinerja karyawan. Punishment adalah sanksi yang diterima oleh seorang karyawan karena ketidakmampuannya dalam mengerjakan atau melaksanakan pekerjaan sesuai dengan yang diperintahkan. Setiap pekerjaan yang dibebankan pada seorang karyawan adalah sesuai dengan ketentuan yang ditegaskan diawal sekali ketika karyawan tersebut bekerja di perusahaan tersebut, terutama pada saat karyawan tersebut menandatangani perjanjian kesanggupan untuk bersedia bekerja sesuai dengan perintah dari surat keputusan yang digariskan tersebut. 
Dalam suatu kegiatan perusahaan pemberian Punishment/ hukuman merupakan kegiatan yang lumrah, sebab punishment bertujuan mendisiplinkan setiap karyawan agar bertindak sesuai dengan peraturanperaturan dan tata cara perilaku yang telah ditetapkan perusahaan. Pada beberapa kondisi tertentu, penggunaan punishment dapat lebih efektif untuk merubah perilaku karyawan yang menyimpang karena dalam penerapan punishment dimaksudkan dapat menimbulkan efek jera kepada pelanggar. Semakin tinggi tingkat punishment seseorang maka semakin menurun pula tingkat kinerja karyawan karena merasa tertekan.

PT Unilever Indonesia Tbk merupakan perusahaan yang ber-gerak dalam bidang penyediaan consumer produk yang telah tum-buh menjadi salah satu perusahaan terkemuka di Indonesia. PT Uni-lever Indonesia Tbk mempunyai komitmen yaitu menjadikan sumber daya manusia menjadi prioritas perusahaan untuk mengembangkan profesionalisme dan keseimbangan hidup, sehingga Perusahaan ini mempunyai prospek yang baik dalam mempertahankan karyawan untuk jangka waktu panjang untuk pengembangan sumber daya manusia yang lebih baik.

Berdasarkan uraian di atas, maka perusahaan harus terus mampu meningkatkan kinerja karyawan agar dapat mempertahan-kan eksistensi tersebut dengan salah satu cara yaitu memberikan reward dan punishment kepada karyawan. Penerapan sistem re-ward atau penghargaan kepada karyawan yang berprestasi akan memberikan motivasi kepada karyawan untuk lebih meningkatkan kinerja dalam bekerja. Perusahaan juga harus menerapkan sanksi atau punishment kepada karyawan yang malas dan lalai dalam bekerja karena hal itu akan mengganggu kinerja karyawan yang lain. Sanksi atau punishment adalah hukuman yang diberikan karena adanya pelanggaran terhadap yang berlaku.
Perusahaan tidak bisa memberikan reward dan punishment hanya berdasarkan suka atau tidak suka. Pemberian reward dan punishment yang tidak adil akan menyebabkan kecemburuan sosial yang timbul diantara karyawan sehingga akan memicu hubungan kerja yang negatif dan tentunya berdampak pada kinerja karyawan.

Setelah peneliti melakukan prapenelitian di PT. Unilever Indonesia tbk Jakarta khususnya di Divisi Field Execution Manage-ment. Pada Divisi ini karyawan mempunyai target penjualan dan tar-get untuk melakukan development terhadap customer. Maka, sering terlihatnya fenomena masalah yang mengakibatkan menurunnya atau kurangnya kemampuannya karyawan dalam mengerjakan atau melaksanakan tugas sehingga hasil yang diberikan tidak sesuai dengan yang diperintahkan. Hal ini disebabkan oleh faktor reward dan punishment yang tidak berjalan baik. Seperti masalah reward yaitu lambat nya appraisal kenaikan level bagi karyawan yang pres-tasi nya sudah bagus, seharusnya apabila karyawan loyal terhadap perusahaan perusahaan akan memberikan reward yang lebih kepada mereka. Apabila reward tidak sesuai maka akan sangat mempengaruhi kinerja karyawan kedepannya.

Selain itu masalah punishment yang terjadi diperusahaan ini adalah adanya sikap tidak disiplin yang sering dilakukan karyawan di Divisi Field Execution Management selama bekerja, salah satu nya datang atau bekerja tidak tepat waktu karena tidak adanya absensi yang ketat karena lebih banyak kegiatan utama ya berada di lapangan sehingga tidak terecord jam bekerja nya. Sehingga terjadinya peningkatan jumlah surat peringatan (SP) yang dibuat untuk Karya-wan dan mempengaruhi penilaian performance kinerja. Hal lain, ma-salah punishment yang terjadi adalah apabila karyawan tidak men-capai target yang ditentukan, maka tidak keluarnya bonus 
tambahan yang diberikan perusahaan kepada mereka

\section{Reward}

Reward atau penghargaan meliputi banyak dari perangsang yang disediakan oleh organisasi untuk karyawan sebagai bagian dari kon-trak psikologis. Penghargaan juga memuaskan sejumlah kebutuhan yang berusaha untuk dipenuhi oleh karyawan melalui pilihan mereka atas perilaku terkait pekerjaan (Moorhead \& Griffin, 2013). Menurut Faldian (2011) reward atau penghargaan adalah sebuah bentuk apre-siasi kepada suatu prestasi tertentu yang diberikan, baik oleh dan dari perorangan ataupun suatu lembaga yang biasanya diberikan dalam bentuk material atau ucapan. Menurut Eni Nurmiyati (2010: 99) Re-ward memiliki pengertian ganjaran, hadiah, penghargaan atau imba-lan

\section{Punishment}

Menurut Mangkunegara (dalam Koencoro, 2012: 3) "punishment adalah ancaman hukuman yang bertujuan untuk memperbaiki kinerja pelanggar, memelihara peraturan yang berlaku dan memberikan pelajaran kepada pelanggar".

Menurut Ivancevich, Konopaske dan Matteson (dalam Koencoro, 2012: 3) "punishment didefinisikan sebagai tindakan menyajikan konsekuensi yang tidak menyenangkan atau tidak diinginkan sebagai hasil dari dilakukanya perilaku tertentu". Pada beberapa kondisi tertentu, penggunaan punishment dapat lebih efektif untuk merubah perilaku Karyawan yang menyimpang karena dalam penerapan punishment dimaksudkan dapat menimbulkan efek jera kepada pelanggar.

Menurut Sardiman (2011: 94) Punishment adalah salah satu bentuk penguatan (reinforcement) negatif yang menjadi alat motivasi jika diberikan secara tepat dan bijak sesuai dengan prinsip-prinsip pemberian hukuman atau punishment.

\section{Kinerja Karyawan}

Menurut Mangkunegara (2011: 67) kinerja adalah hasil kerja secara kualitas dan kuantitas yang dicapai oleh seorang pegawai dalam melaksanakan tugasnya sesuai dengan tanggung jawab yang diberikan kepadanya. Adapun kinerja menurut Wibowo (2012: 7) adalah tentang melakukan pekerjaan dan hasil yang di capai dari pekerjaan tersebut. Dengan kata lain kinerja adalah tentang apa yang dikerjakan dan bagaimana cara mengerjakannya.

Demikian pula menurut Siagian (2012: 168), bahwa kinerja sebagai suatu keadaan yang menunjukkan kemampuan seseorang karyawan dalam menjalankan tugas sesuai dengan standar yang telah ditentukan oleh organisasi kepada karyawan sesuai dengan job description-nya.

Sinambela, dkk (2012) mengemukakan bahwa kinerja pegawai didefinisikan sebagai kemampuan pegawai dalam melakukan sesuatu keahlian tertentu. Kinerja pegawai sangatlah perlu, sebab dengan kinerja ini akan diketahui seberapa jauh kemampuan pegawai dalam melaksanakan tugas yang dibebankan kepadanya. Untuk itu diperlukan penentuan kriteria yang jelas terstrukur serta ditetapkan secara bersama-sama yang dijadikan sebagai acuan..

\section{METODE}

Penelitian ini termasuk jenis penelitian kuantitatif. Metode analisis data menggunakan analiasi Structural Equation Modeling- Partial Least Square (SEM-PLS) software Smart PLS versi 3. Populasi dalam penelitian ini adalah Karyawan PT Unilever Indonesia, Tbk Jakarta Divisi Field Execution Management. Teknis pengambilan sampel adalah Probability Sampling dengan metode Total Sampling, dengan jumlah 
sampel sebanyak 82 responden. Adapun tahap-tahap pengujiannya adalah uji validitas, uji reliabilitas, dengan Teknik uji model meliputi inner model dan outer model.

\section{HASIL}

Berdasarkan penelitian yang telah dilakukan maka didapat hasil Uji Validitas Reward (X1), Punishment (X2) dan Kinerja Karyawan (Y) pada Tabel 1.

\section{Outer Model}

Uji Validitas

Tabel 1.

Uji Validitas Reward (X1), Punishment (X2) dan Kinerja Karyawan (Y)

\section{Uji Reabilitas}

\begin{tabular}{|c|c|c|c|c|c|}
\hline & $\begin{array}{l}\text { Original } \\
\text { Samplo } \\
\text { (o) }\end{array}$ & $\begin{array}{l}\text { Samplô, } \\
\text { Mean (Mi) }\end{array}$ & $\begin{array}{l}\text { Standard } \\
\text { Doviation } \\
\text { (STDEV) }\end{array}$ & $\begin{array}{l}\text { Standard } \\
\text { (STEror }\end{array}$ & values \\
\hline $\begin{array}{l}\times 1,1<- \text { Reward } \\
(\times 1)\end{array}$ & 0.808 & 0.811 & 0.061 & 13.314 & 0.000 \\
\hline $\begin{array}{l}x 1,2<- \text { Reward } \\
(x i))\end{array}$ & 0.818 & 0.822 & 0.054 & 15.213 & 0.000 \\
\hline $\begin{array}{l}\times 1,3<- \text { Reward } \\
(\times 1)^{3}\end{array}$ & 0.786 & 0.795 & 0.083 & 12.396 & 0.000 \\
\hline $\begin{array}{l}\times 1,4<- \text { Reward } \\
(\times 1)\end{array}$ & 0.784 & 0.783 & 0.075 & 10.454 & 0.000 \\
\hline $\begin{array}{l}\times 1,5<- \text { Reward } \\
(\times 1)\end{array}$ & 0.811 & 0.808 & 0.052 & 15.634 & 0.000 \\
\hline $\begin{array}{l}\times 1,6<- \text { Reward } \\
(\times i)\end{array}$ & 0.762 & 0.754 & 0.082 & 9.344 & 0.000 \\
\hline $\begin{array}{l}\times 1 i)^{\prime}<- \text { Reward } \\
\left(x^{\prime}\right.\end{array}$ & 0.516 & 0.528 & 0.100 & 5.163 & 0.000 \\
\hline $\begin{array}{l}\times 1 \text { i }<- \text { Reward } \\
(\times 1)\end{array}$ & 0.734 & 0.743 & 0.086 & 8.567 & 0.000 \\
\hline $\begin{array}{l}\times 1.1 \text { is- } \\
\text { Punishment }(\times 2)\end{array}$ & 0.899 & 0.902 & 0.028 & 32.478 & 0.000 \\
\hline $\begin{array}{l}\times 1,2=- \\
\text { Punishment ( }\end{array}$ & 0.848 & 0.848 & 0.049 & 17.251 & 0.000 \\
\hline $\begin{array}{l}\times 1.3<- \\
\text { Punishment ( }\end{array}$ & 0.596 & 0.620 & 0.142 & 4.195 & 0.000 \\
\hline $\begin{array}{l}\times 1.4 \text { - } \\
\text { Punishment ( } \times 2)\end{array}$ & 0.780 & 0.775 & 0.079 & 9.860 & 0.000 \\
\hline $\begin{array}{l}\times 1,5 \text { - } \\
\text { Punishment ( } \times 2)\end{array}$ & 0.655 & 0.656 & 0.112 & 5.366 & 0.000 \\
\hline $\begin{array}{l}\times 1.6 \text { - } \\
\text { Punishment ( } \times 2)\end{array}$ & 0.794 & 0.800 & 0.043 & 18.508 & 0.000 \\
\hline $\begin{array}{l}\text { Y1<-Kinerja) } \\
\text { Karyawan (Y) }\end{array}$ & 0.774 & 0.776 & 0.070 & 11.097 & 0.000 \\
\hline $\begin{array}{l}\text { YZu- Kinerja } \\
\text { Karyawan (Y) }\end{array}$ & 0.654 & 0.667 & 0.105 & 6.239 & 0.000 \\
\hline $\begin{array}{l}\text { Y3 Kineria } \\
\text { Karyawan (Y) }\end{array}$ & 0.633 & 0.654 & 0.092 & 6.854 & 0.000 \\
\hline $\begin{array}{l}\text { Y4<-Kinerja, } \\
\text { Karyawan (Y) }\end{array}$ & 0.789 & 0.796 & 0.067 & 11.730 & 0.000 \\
\hline $\begin{array}{l}\text { Yo-kinerja } \\
\text { Karyawan (Y) }\end{array}$ & 0.779 & 0.784 & 0.078 & 10.023 & 0.000 \\
\hline $\begin{array}{l}\text { Ye-Kinerja } \\
\text { Karyawan (Y) }\end{array}$ & 0.791 & 0.790 & 0.070 & 11.249 & 0.000 \\
\hline $\begin{array}{l}\text { Y7-Kinerja, } \\
\text { Karyawan (Y) }\end{array}$ & 0.792 & 0.794 & 0.077 & 10.350 & 0.000 \\
\hline $\begin{array}{l}\text { Yo-kinerja } \\
\text { Karyawan (Y) }\end{array}$ & 0.718 & 0.718 & 0.095 & 7.569 & 0.000 \\
\hline
\end{tabular}

\section{Hasil Uji Reabilitas}

\begin{tabular}{|l|c|c|c|c|}
\hline & $\begin{array}{c}\text { Cronbach's } \\
\text { Alpha }\end{array}$ & rho_A & $\begin{array}{c}\text { Composite } \\
\text { Reliability }\end{array}$ & $\begin{array}{c}\text { Average } \\
\text { Variance } \\
\text { Extracted } \\
\text { (AVE) }\end{array}$ \\
\hline Reward & 0.884 & 0.891 & 0.908 & 0.553 \\
\hline Punishment & 0.858 & 0.892 & 0.895 & 0.592 \\
\hline $\begin{array}{l}\text { Kinerja } \\
\text { Karyawan }\end{array}$ & 0.891 & 0.903 & 0.914 & 0.575 \\
\hline
\end{tabular}

Inner Model

Uji Path Coefficient 


\section{R-Square}

\begin{tabular}{|l|c|c|}
\hline & R Square & R Square Adjusted \\
\hline Kinerja Karyawan & 0.907 & 0.904 \\
Punishment & 0.548 & 0.540 \\
\hline
\end{tabular}

\section{Uji Hipotesis}

\section{Path Coefficient}

\begin{tabular}{|l|c|c|c|c|c|c|}
\hline & $\begin{array}{c}\text { Original } \\
\text { Sample } \\
(\mathrm{O})\end{array}$ & $\begin{array}{c}\text { Sample } \\
\text { Mean } \\
(\mathrm{M})\end{array}$ & $\begin{array}{c}\text { Standard } \\
\text { Deviation } \\
\text { (STDEV) }\end{array}$ & $\begin{array}{c}\text { T Statistics } \\
(\mid \mathrm{O} / \\
\text { STDEV } \mid)\end{array}$ & $\begin{array}{c}\mathrm{P} \\
\text { Values }\end{array}$ & Ket \\
\hline $\begin{array}{l}\text { Reward }-> \\
\text { Kinerja } \\
\text { Karyawan }\end{array}$ & 0.631 & 0.620 & 0.100 & 6.288 & 0.000 & Significant \\
\hline $\begin{array}{l}\text { Punishment } \\
\text { - Kinerja } \\
\text { Karyawan }\end{array}$ & 0.386 & 0.393 & 0.101 & 3.827 & 0.000 & Significant \\
\hline $\begin{array}{l}\text { Reward -> } \\
\text { Punishment }\end{array}$ & 0.740 & 0.766 & 0.077 & 9.643 & 0.000 & Significant \\
\hline
\end{tabular}

\section{Pengaruh Reward terhadap Kinerja Karyawan}

Hipotesis pertama menguji apakah Reward secara positif berpengaruh terhadap Kinerja Karyawan. Hasil pengujian menunjukkan nilai original sample 0,631 dan T Statistics 6,288 > 1,96 T-Table dan PValues $=0.000(<0,05)$. Hasil hipotesis menunjukkan bahwa reward berpengaruh positif dan signifikan terhadap kinerja karyawan terbukti kebenarannya atau $\mathrm{H} 1$ diterima

\section{Pengaruh Punishment terhadap Kinerja Karyawan}

Hipotesis kedua menguji apakah Punishmnet secara positif berpengaruh terhadap Kinerja Karyawan. Hasil pengujian menunjukkan nilai original sample 0,386 dan T Statistics 3,827 > 1,96 T-Table dan PValues $=0.000(<0,05)$. Hasil hipotesis menunjukkan bahwa punishment berpengaruh positif dan signifikan terhadap kinerja karyawan terbukti kebenarannya atau $\mathrm{H} 2$ diterima.

\section{Pengaruh Reward terhadap Punishment}

Hipotesis ketiga menguji apakah Reward secara positif berpengaruh terhadap Punishment. Hasil pengujian menunjukkan dan signifikan terhadap punishment yang ditunjukkan dengan nilai original sample 0,740 dan T Statistics 9.643 > 1,96 T-Table dan P-Values $=0.000(0,05)$. Hasil hipotesis menyatakan bahwa reward berpengaruh positif dan signifikan terhadap punishment terbukti kebenarannya atau $\mathrm{H} 3$ diterima.

\section{KESIMPULAN DAN SARAN}

\section{Kesimpulan}


1. Hasil penelitian menunjukkan bahwa pengaruh antara reward terhadap kinerja karyawan adalah signifikan. Demikian H1 dalam penelitian ini diterima. Artinya reward berpengaruh positif dan signifikan terhadap kinerja karyawan.

2. Hasil penelitian menunjukkan bahwa pengaruh punishment terhadap kinerja karyawan adalah signifikan. Demikian $\mathrm{H} 2$ dalam penelitian ini diterima. Artinya punishment dapat meningkatkan kinerja karyawan.

3. Hasil penelitian menunjukkan bahwa pengaruh antara reward dan punishment adalah signifikan. Demikian H3 dalam penelitian ini diterima. Artinya reward berpengaruh terhadap punishment.

\section{Saran}

1. Hendaknya, PT. Unilever Indonesia Tbk Jakarta Divisi Field Execution Management perlu untuk lebih meningkatkan pemberian reward berupa penghargaan psikologis dengan cara pemberian apresiasi seperti pujian, sanjungan, dan ucapan selamat yang dirasakan pegawai sebagai bentuk pengakuan terhadap dirinya sehingga mendatangkan kepuasan bagi dirinya sendiri.

2. Hendaknya, PT. Unilever Indonesia Tbk Jakarta Divisi Field Execution Management mengimplementasikan secara tegas sanksi dan teguran terhadap karyawan yang sering datang terlambat berupa surat peringatan (SP) sebagai bentuk bimbingan dan penyuluhan bagi karyawan dalam menciptakan tata tertib yang baik di perusahaan atau instansi, dimana dengan tata tertib yang baik, maka semangat kerja, moril kerja, efisiensi dan efektivitas kerja karyawan akan meningkat. Selain perlu ditambahkan mekanisme absen untuk karyawan yang bekerja langsung ke lapangan, seperti absen melalui system online via handphone sehingga terecord jam kerja nya.

3. Hendaknya, PT. Unilever Indonesia Tbk Jakarta Divisi Field Execution Management perlu terus memberikan motivasi kerja terhadap pegawai dan memberikan kesempatan kepada pegawai untuk mengikuti pendidikan dan pelatihan agar mampu membekali dirinya untuk melaksanakan tugas-tugas yang dibebankan serta berani mengambil resiko.

\section{DAFTAR PUSTAKA}

1. A.M. Sardiman. 2011. Interaksi dan Motivasi Belajar Mengajar. Jakarta: PT Rajagrafindo

2. Abdillah., W dan Jogiyanto. 2009. Partial Least Square (PLS) Alternatif SEM Dalam Penelitian Bisnis. Penerbit Andi: Yogyakarta. Hal 262.

3. Amron \& Taufiq Imran. 2009. Analisis Faktor- Faktor yang Berpengaruh Terhadap Produktivitas Tenaga kerja Outlet Telekomunikasi Seluler Kota Makassar.Jurnal Sekolah Tinggi Ilmu Ekonomi Nobel Indonesia.

4. Adri Saputra, Sigid. 2010. Pengaruh Kompensasi, Kepuasan Kerja, Dan Motivasi Kerja Terhadap Kinerja Karyawan Bagian Akuntansi Pada Perusahaan Umum Di Surabaya Dan Sidoarjo. Skripsi Stie Perbanas Surabaya.

5. Arikunto, S. 2002. Metodologi Penelitian Suatu Pendekatan Proposal. Jakarta: PT. Rineka 
Cipta.

6. Arikunto, S. 2006. Metode Penelitian Kualitatif. Jakarta: Bumi Aksara

7. Bangun, Wilson. 2012. Manajemen Sumber Daya Manusia. Jakarta: Erlangga.

8. Busro, Muhammad. 2018. Teori Manajemen Sumber Daya Manusia. Jakarta: Prenada Media.

9. Eni Nurmiyati. 2011. Hubungan Pemberian Reward dan Punishment dengan Kinerja Karyawan pada BPRS Harta Insan Karimah. Skripsi. Jakarta: Fakultas Syariah dan Hukum.

10. Faldian, Rahmanda Putra, dkk. 2013.Pengaruh Insentif Terhadap Motivasi dan Kinerja Karyawan Studi Pada Karyawan PT. Jamsostek (Persero) Cabang Malang. Malang: Fakultas IImu Administrasi Universitas.

11. Gendro,Wiyono. 2011. Merancang Penelitian Bisnis dengan Alat Analisis SPSS

17.0 \& Smart PLS 2.0. Yogyakarta: Percetakan STIM YKPM.

12. Gibson. 2013. Penilaian Kinerja. Jakarta: Penerbit Erlangga.

13. Ghozali,I. 2006. Struktural Equation Modeling: Motode Alternatif dengan PLS. Semarang: Universitas Diponegoro.

14. Ghozali, Imam. 2008. Structural
Equation Modelling, Edisi II, Universitas Diponegoro, Semarang.

15. Hair, J.F. 1998. Multivariate Data Analysis. Fifth Edition, Internasional Edition. Prentice Hall.

16. Handoko, 2013, Manajemen; Edisi Kedua, Cetakan Ketigabelas, BPFE Yogyakarta.

17. Handoko, T.H. 2012. Pengantar Manajemen. Yogyakarta: BPFE.

18. Handoko, T. Hani. 2011. Manajemen Personalia dan Sumberdaya Manusia. Yogyakarta: Penerbit BPFE.

19. Hasibuan, Malayu S.P, 2011. Manajemen Sumber Daya Manusia. Jakarta: PT Bumi Askara.

20. Hasibuan, M.S.P. 2012. Manajemen Sumber Daya Manusia. Jakarta: Bumi Aksara.

21. Ivancevich, Konopaske Dan Matteson. 2006. Perilaku Manajemen Dan Organisasi. Alih bahasa Gina Gania. Jakarta : Erlangga.

22. Karami, A., Dolatabadi, H.R., and Rajaeepour, S., 2013, "Analyzing the Effectiveness of Reward Management System on Employee Performance through the Mediating Role of Employee Motivation Case Study: Isfahan Regional Electric Company", International 
Journal of Academic Research in Business and Social Sciences, Vol. 3 (9), pp. 327338.

23. Koencoro, Galih Dwi. 2013. Pengaruh Reward dan Punishment Terhadap Kinerja. Skripsi. Universitas Brawijaya.

24. Kadarisman, M. 2012. Manajemen kompensasi. Jakarta: Rajawali pers.

25. Mahmudi. 2013. Manajemen Kinerja Sektor Publik. Sekolah Tinggi Ilmu Manajemen YKPN, Yogyakarta.

26. Mangkunegara, A.A. Anwar Prabu. 2011. Manajemen Sumber Daya Manusia Perusahaan. Bandung: Rosda

27. Mangkunegara, A.A. Anwar Prabu. 2012. Evaluasi Kerja Sumber Daya Manusia cetakan ke enam. Bandung: Refika Aditama

28. Mangkunegara, A.A. Anwar Prabu. 2013. Manajemen Sumber Daya Manusia Perusahaan. Bandung: Remaja Rosdakarya.

29. Martono, Nanang. 2015. Metode Penelitian Sosial. Jakarta: Rajawali Pers.

30. Mathis, R. L., \& Jackson, J. H. 2011. Human Resources Management. United States: South-Western Cengage Learning.
31. Moorhead, Gregory \& Ricky W. Griffin, 2013. Perilaku Organisasi. Jakarta: Salemba Empat.

32. R.Cooper, Donald: S.Schindler, Pamela. 2006. "Business Research Methods", $9^{\text {th }}$ edition. McGraw-Hill International Edition.

33. Siagian. Sondang P. 2012. Manajemen Sumber Daya Manusia. Jakarta: Bumi Aksara.

34. Simanjuntak, P. F. 2012. Pengaruh Penilaian Prestasi Kerja Terhadap Motivasi Kerja Karyawan PT Putrimega Asriindah. Skripsi. Fakultas Ekonomi, Universitas Sumatera Utara.

35. Simanjuntak, Payaman. J. 2001. Pengantar Ekonomi Sumber Daya Manusia. Jakarta: Lembaga Penerbit Fakultas Ekonomi Ul.

36. Purwanto, Ngalim. Purwanto, Ngalim. 2013. Prinsip-Prinsip dan Teknik Evaluasi Pengajaran. Bandung: PT Remaja Rosdakarya.

37. Sugiyono. 2010. Metode Penelitian Bisnis. Bandung: CV. Alfabeta.

38. Sugiyono. 2013. Metode Penelitian Kuantitatif Kualitatif dan R\&D. Bandung: CV Alfabeta.

39. Sugiyono. 2014. Metode Penelitian 
Manajemen. Bandung : Alfabeta.

40. Sugiyono. 2015. Metode Penelitian Pendidikan (Pendekatan Kuantitatif, Kualitatif dan R\&D). Penerbit CV. Alfabeta: Bandung.

41. Sedermayanti. 2011. Manajemen Sumber Daya Manusia, Reformasi Birokrasi Manajemen Pegawai Negeri Sipil. Bandung: Penerbit Refika Aditama.

42. Siregar. Syofian. 2014. Metode penelitian kuantitatif dilengkapi dengan perbandingan perhitungan manual dan SPSS. Jakarta: Kencana.
Kinerja. Jakarta: raja Grafindo Persada.

46. Widodo, S. E. 2015. Manajemen Pengembangan Sumber Daya Manusia. Yogyakarta: Pusaka Pelajar.

47. Unilever Indonesia, https://www.unilever.co.id/

48. Jurnal Manajement Bisnis dan Kewirausahaan/Volume 01/No.2/November-2017: 132147

49.

Core.ac.uk/download/pdf/1172 3365.pdf

43. Sondang P. Siagian. 2013. Manajemen Sumber Daya Manusia. Jakarta: Bumi Aksara.

44. Vincenzo. 2010. Handbook of Partial Least Square. SpringerVerlag Berlin Heidelberg.

45. Wibowo. 2012. Manajemen 